\title{
Spin-Triplet Cobalt Complexes of Biuret and Related Ligands
}

\section{P. J. M. W. L. BIRKER, J. J. BOUR, and J. J. STEGGERDA*}

Received October 3, 1972

\begin{abstract}
A number of planar $\mathrm{Co}^{\mathrm{III}} \mathrm{N}_{4}$ complexes have been prepared with biuret and $\mathrm{N}$-substituted biurets. They are shown to have triplet electronic ground states in the temperature range $6.4-293^{\circ} \mathrm{K}$. The zero-field splitting is estimated to be about $40 \mathrm{~cm}^{-1}$. The triplet ground state is consistent with molecular orbital energies obtained from extended Huckel calculations. The $d_{x z}$ and $d_{x^{2}-y^{2}}$ orbitals both have the same energy and are both occupied by one electron. Polarographic measurements show that these complexes can be reversibly reduced in a one-electron step. With amines, diamagnetic sixcoordinated mixed-ligand species are obtained, whose uv-vis spectra can be interpreted as for Co(III) in an octahedral environment.
\end{abstract}

\section{Introduction}

In previous communications from our laboratory the rather unique properties of biuret as a ligand were discussed. It was shown that the well-known $\mathrm{Cu}$ (II) and $\mathrm{Ni}$ (II) complexes could be oxidized with various oxidizing agents yield- ing the corresponding $\mathrm{Cu}$ (III) and $\mathrm{Ni}$ (III) compounds. ${ }^{1,2}$ With cobalt the very remarkable planar bis(biuretato)cobalt-

(1) J. J. Bour and J. J. Steggerda, Chem. Commun., 85 (1967). (2) J. J. Bour, P. J. M. W. L. Birker, and J. J. Steggerda, Inorg. Chem., 10, 1202 (1971). 
ate(III) ion could be synthesized having a spin-triplet ground state. ${ }^{1,3}$ The crystal structure of the 3- $n$-propyl-substituted biuret complex of $\mathrm{Co}$ (III) was recently published. ${ }^{4}$ We now report more details about the properties of a series of cobalt complexes with biuret and related ligands.

\section{Experimental Part}

Abbreviations. Abbreviations used in this paper are as follows: $\mathrm{bi}=[\mathrm{HNCONHCONH}]^{2-}, 3-\mathrm{Ph}(\mathrm{bi})=\left[\mathrm{HNCON}\left(\mathrm{C}_{6} \mathrm{H}_{5}\right) \mathrm{CONH}\right]^{2-}$ $3-\operatorname{Pr}(\mathrm{bi})=\left[\mathrm{HNCON}\left(\mathrm{C}_{3} \mathrm{H}_{7}\right) \mathrm{CONH}\right]^{2-}, 1-\operatorname{Pr}(\mathrm{bi}) \mathrm{H}_{2}=\mathrm{H}_{2} \mathrm{NCONHCONHC}_{3}$. $\mathbf{H}$,

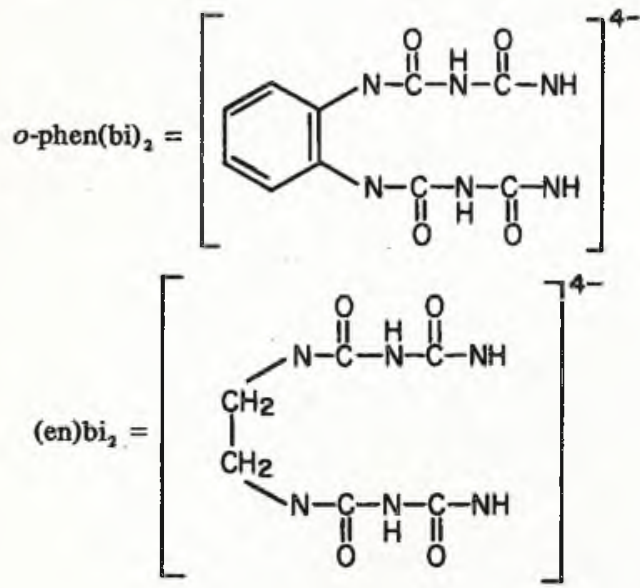

DMSO $=$ dimethyl sulfoxide and $\mathrm{Bu}_{4} \mathrm{NOH}=$ tetra- $n$-butylammonium hydroxide.

Syntheses. o-Phenylenebis(biuret) and Ethylenebis(biuret). These ligands were obtained in a way analogous to the method used for the preparation of 1-alkyl-substituted biuret ${ }^{5}$ starting with a 2:1 mixture of nitrobiuret and $o$-phenylenediamine or ethylenediamine, respectively.

$\mathrm{KCo}(\mathrm{bi})_{2}$. Cobalt acetate $(25 \mathrm{~g})$ was dissolved in $25 \mathrm{ml}$ of water. Biuret $(30 \mathrm{~g})$ and $\mathrm{KOH}(36 \mathrm{~g}$, dissolved in $50 \mathrm{ml}$ of water) were added to this solution and the resulting blue slurry was oxidized with air during $24 \mathrm{hr}$. The insoluble material was then removed by filtration and upon careful neutralization with $6 \mathrm{~N} \mathrm{HCl}$ to $\mathrm{pH} 7 \mathrm{KCo}(\mathrm{bi})_{2}$ precipitated as a yellow compound. It was filtered off, washed with water, and dried in a vacuum desiccator. The compound is insoluble in any solvent.

Anal. Calcd for $\mathrm{KCo}(\mathrm{bi})_{2}$ : $\mathrm{K}, 13.03 ; \mathrm{Co}, 19.65 ; \mathrm{C}, 16.00 ; \mathrm{H}$, $2.00 ; \mathrm{N}, 28.00$. Found: $\mathrm{K}, 13.4 ; \mathrm{Co}, 19.3 ; \mathrm{C}, 15.7 ; \mathrm{H}, 2.2 ; \mathrm{N}$, 27.2

KCo(3-Ph(bi)) ${ }_{2}$-2DMSO. 3-Phenylbiuret was prepared according to Weith. ${ }^{6} \mathrm{CoCl}_{2} \cdot 6 \mathrm{H}_{2} \mathrm{O}(2.4 \mathrm{~g})$ and 3-phenylbiuret $(5.1 \mathrm{~g})$ were dissolved in $100 \mathrm{ml}$ of water. $\mathrm{KOH}(3.6 \mathrm{~g}$ dissolved in $5 \mathrm{ml}$ of water) was added to this solution. The resulting blue slurry was oxidized with air during $24 \mathrm{hr}$. Then the insoluble material was removed by filtration. To the red filtrate about the same volume of alcohol was added and then sufficient ether was added to form red and colorless liquid layers. The upper colorless layer was removed, alcohol and ether again were added, and the same procedure was repeated several times until finally a red precipitate was obtained. This precipitate was dissolved in DMSO. Within a few minutes the color of the solution turned from red to yellow. The solution was filtered and the yellow complex was precipitated by adding chloroform and ether. It was filtered off in dry air and washed with chloroform and ether. It is soluble in acetone, alcohol, and DMSO.

Anal. Calcd for $\mathrm{KCo}(3-\mathrm{Ph}(\mathrm{bi}))_{2} \cdot 2 \mathrm{DMSO}: \mathrm{Co}, 9.8 ; \mathrm{C}, 39.6 ; \mathrm{H}$, 4.28; $\mathrm{N}, 13.8$. Found: $\mathrm{Co}, 9.3 ; \mathrm{C}, 39.4 ; \mathrm{H}, 4.25 ; \mathrm{N}, 13.5$.

$\mathrm{Bu}_{4} \mathrm{NCo}(3-\mathrm{Ph}(\mathrm{bi}))_{2} \cdot \mathrm{CoCl}_{2} \cdot 6 \mathrm{H}_{2} \mathrm{O}(0.8 \mathrm{~g})$ and 3-phenylbiuret $(1.7 \mathrm{~g})$ were dissolved in $100 \mathrm{ml}$ of water. A 40-ml sample of a $40 \%$ $\mathrm{Bu}_{4} \mathrm{NOH}$ solution in water was added and the resulting mixture was oxidized with air during $24 \mathrm{hr}$. Then the insoluble material was

(3) J. J. Steggerda and J. J. Bour, Proc. Symp. Coord. Chem., $274(1970)$

(4) J. J. Bour, P. T. Beurskens, and J. J. Steggerda, J. Chem. Soc., Chem. Commun., 221 (1972).

(5) T. L. Davis and K. C. Blanchard, J. Amer. Chem. Soc., 51, 1804 (1929).

(6) W. Weith, Ber., 10, 1744 (1877). filtered off and the red filtrate was concentrated as described above with alcohol and ether finally yielding a red precipitate, that was dissolved in DMSO. Dropwise aqueous $1 N \mathrm{HCl}$ was added to this red solution until the color had turned to orange-yellow. The complex was then precipitated by adding a little alcohol and much ether. The precipitate was filtered off. It was dissolved in chloroform, the solution was filtered, and the complex was again precipitated by adding ether.

Anal. Calcd for $\mathrm{Bu}_{4} \mathrm{NCo}(3-\mathrm{Ph}(\mathrm{bi}))_{2}: \mathrm{C}, 58.61 ; \mathrm{H}, 7.69 ; \mathrm{N}$, 14.95. Found: $C, 58.2 ; H, 7.7 ; \mathrm{N}, 14.9$.

$\mathrm{Bu}_{4} \mathrm{NCO}(\mathrm{bi})_{2} \cdot \mathrm{H}_{2} \mathrm{O} . \mathrm{CoCl}_{2} \cdot 6 \mathrm{H}_{2} \mathrm{O}(5 \mathrm{~g})$ was dissolved in $200 \mathrm{ml}$ of water. Biuret $(6 \mathrm{~g})$ and $75 \mathrm{ml}$ of a $40 \% \mathrm{Bu}_{4} \mathrm{NOH}$ solution in water were added. The resulting mixture was oxidized with air during $4 \mathrm{hr}$. The insoluble material was filtered off and the red filtrate was concentrated with alcohol and ether as described above until a volume of about $20 \mathrm{ml}$ of the red solution was left. To this solution $50 \mathrm{ml}$ of DMSO was added and $1 N \mathrm{HCl}$ was dropped into the solution until the color of the solution was orange-yellow. The complex was precipitated by adding alcohol and ether and filtered off. For purification it was dissolved in DMSO, the solution was filtered, and the complex was again precipitated with chloroform and ether, filtered off, and washed with chloroform.

Anal. Calcd for $\mathrm{Bu}_{4} \mathrm{NCo}(\mathrm{bi})_{2} \cdot \mathrm{H}_{2} \mathrm{O}: \quad \mathrm{C}, 46.0 ; \mathrm{H}, 8.4 ; \mathrm{N}, 18.8$. Found: $\mathrm{C}, 45.6 ; \mathrm{H}, 7.9 ; \mathrm{N}, 18.8$.

$\mathrm{KCO}(3-\operatorname{Pr}(\mathrm{bi}))_{2}\left(1-\operatorname{Pr}(\mathrm{bi}) \mathrm{H}_{2}\right)_{2}$. When the method of Weith ${ }^{6}$ for the preparation of 3-phenylbiuret is used for the preparation of alkylbiurets, a mixture of 1-alkylbiuret and 3-alkylbiuret is always obtained. So when a mixture of $0.1 \mathrm{~mol}$ of very dry propylurea and $0.1 \mathrm{~mol}$ of $\mathrm{PCl}_{3}$ is refluxed during $4 \mathrm{hr}$, a acid solution containing 1-propylbiuret and 3-propylbiuret is obtained after hydrolysis of the reaction mixture with ice. In such a solution excess $\mathrm{CoCl}_{2}{ }^{\circ}$ $6 \mathrm{H}_{2} \mathrm{O}$ was dissolved. KOH was added until a blue slurry was formed, which was oxidized with air during $24 \mathrm{hr}$. The precipitate was filtered off and upon careful neutralization of the red solution with $6 N \mathrm{HCl}$ to $\mathrm{pH} \mathrm{7,} \mathrm{the} \mathrm{yellow} \mathrm{complex} \mathrm{precipitated.} \mathrm{It} \mathrm{was} \mathrm{filtered}$ off and washed with water. The complex is soluble in DMSO, alcohol, and acetone.

Anal. Calcd for $\mathrm{KCo}(3-\mathrm{Pr}(\mathrm{bi}))_{2}\left(1-\operatorname{Pr}(\mathrm{bi}) \mathrm{H}_{2}\right)_{2}: \mathrm{Co}, 8.73 ; \mathrm{C}$, $35.31 ; \mathrm{H}, 5.98 ; \mathrm{N}, 24.92$. Found: $\mathrm{Co}, 8.5 ; \mathrm{C}, 35.2 ; \mathrm{H}, 6.1 ; \mathrm{N}$, 25.0 .

In an analogous way other compounds of composition $\mathrm{KCo}$ (3alkyl(bi) $)_{2}$ (1-alkyl(bi) $\left.\mathrm{H}_{2}\right)_{2}$ could be prepared.

$\mathrm{KCO}(3-\operatorname{Pr}(\mathrm{bi}))_{2} \cdot 2 \mathrm{H}_{2} \mathrm{O}$. From a solution of $\mathrm{KCo}(3-\mathrm{Pr}(\mathrm{bi}))_{2}(1-$ $\operatorname{Pr}\left(\text { bi) } \mathrm{H}_{2}\right)_{2}$ in moist DMSO the compound $\mathrm{KCo}(3-\mathrm{Pr}(\mathrm{bi}))_{2} \cdot 2 \mathrm{H}_{2} \mathrm{O}$ precipitated upon addition of chloroform and ether. It was filtered off and washed with chloroform.

Anal. Calcd for $\mathrm{KCo}(3-\mathrm{Pr}(\mathrm{bi}))_{2} \cdot 2 \mathrm{H}_{2} \mathrm{O}$ : Co, $14.0 ; \mathrm{C}, 28.6 ; \mathrm{H}$, 5.3; N, 19.9. Found: Co, $13.9 ; \mathrm{C}, 28.6 ; \mathrm{H}, 4.9 ; \mathrm{N}, 18.8$.

$\mathrm{KCo}(3-\operatorname{Pr}(\mathrm{bi}))_{2} \cdot 2 \mathrm{DMSO}$. In dry DMSO KCo(3-Pr(bi)) ${ }_{2}(1-\operatorname{Pr}(\mathrm{bi})-$ $\left.\mathrm{H}_{2}\right)_{2}$ was dissolved. After a few hours $\mathrm{KCo}(3-\operatorname{Pr}(\mathrm{bi}))_{2} \cdot 2 \mathrm{DMSO}$ could be precipitated by adding dry chloroform. The precipitate was filtered off and washed with chloroform in dry air as it is sensitive to moisture.

Anal. Calcd for $\mathrm{KCo}(3-\operatorname{Pr}(\mathrm{bi}))_{2} \cdot 2 \mathrm{DMSO}: \mathrm{C}, 31.11 ; \mathrm{H}, 5.59$. Found: $\mathrm{C}, 30.9 ; \mathrm{H}, 5.9$.

$\mathrm{KCo}\left(\mathrm{en}(\mathrm{bi})_{2}\right)$. Ethylenebis(biuret) $(1.2 \mathrm{~g})$ and cobalt acetate $(1.2 \mathrm{~g})$ were dissolved in $40 \mathrm{ml}$ of DMSO. To this solution $1.2 \mathrm{~g}$ of $\mathrm{KOH}$ dissolved in $4 \mathrm{ml}$ of water was added. This mixture was oxidized with air during $3 \mathrm{hr}$. The precipitate of the red complex was then filtered off and washed with alcohol. It was dissolved in a lot of warm DMSO. The insoluble material was removed by filtration, and after cooling, the compound could be precipitated by adding a large amount of chloroform. The precipitate was filtered off and washed with chloroform.

Anal. Caled for $\mathrm{KCo}\left(\mathrm{en}(\mathrm{bi})_{2}\right)$ : C, $22.01 ; \mathrm{H}, 2.46 ; \mathrm{N}, 25.7$ Found: $\mathrm{C}, 22.0 ; \mathrm{H}, 2.7 ; \mathrm{N}, 25.0$.

$\mathrm{KCO}(o$-phen(bi) $) . \mathrm{CoCl}_{2} \cdot 6 \mathrm{H}_{2} \mathrm{O}(0.75 \mathrm{~g})$ and $o$-phenylenebis(biuret) $(0.85 \mathrm{~g})$ were dissolved in $60 \mathrm{ml}$ of DMSO. KOH ( $1 \mathrm{~g}$ dissolved in $6 \mathrm{ml}$ of water) was added. This mixture was oxidized with air during $2 \mathrm{hr}$. The solution was filtered and the purple complex was precipitated from the filtrate by adding alcohol. The compound was filtered off and dissolved in DMSO. The solution was filtered, and the complex was again precipitated with alcohol and ether, filtered off, and washed with alcohol.

Anal. Calcd for $\mathrm{KCo}\left(o-\right.$ phen $\left.(\mathrm{bi})_{2}\right)$ : C, $32.09 ; \mathrm{H}, 2.15 ; \mathrm{N}$, 22.46. Found: $C, 31.6 ; \mathrm{H}, 2.3 ; \mathrm{N}, 22.1$.

$\mathrm{Bu}_{4} \mathrm{NCo}\left(\mathrm{en}(\mathrm{bi})_{2}\right)$. Cobalt acetate $(1.2 \mathrm{~g})$ was dissolved in a mixture of $20 \mathrm{ml}$ of water and $10 \mathrm{ml}$ of DMSO. Ethylenebis(biuret) $(1.2 \mathrm{~g})$ and $12.5 \mathrm{ml}$ of a $40 \% \mathrm{Bu}_{4} \mathrm{NOH}$ solution in water were added and the resulting blue slurry was oxidized with air during $12 \mathrm{hr}$. 
Table I. Spectral and Magnetic Data of Triplet Cobalt Complexes

\begin{tabular}{|c|c|c|c|c|c|c|c|}
\hline \multirow[b]{3}{*}{ Compd } & \multicolumn{3}{|c|}{ Magnetic properties $^{a}$} & \multirow{2}{*}{\multicolumn{4}{|c|}{ Uv-vis spectral data $b$}} \\
\hline & \multirow[b]{2}{*}{$\mu_{\mathrm{eff}},{ }^{c} \mathrm{BM}$} & \multirow{2}{*}{$\begin{array}{l}\text { Measd temp range } \\
\text { over which Curie- } \\
\text { Weiss law is } \\
\text { obeyed, }{ }^{\circ} \mathrm{C}\end{array}$} & \multirow[b]{2}{*}{$\Theta,{ }^{\circ} \mathrm{C}$} & & & & \\
\hline & & & & $\nu_{3}, \mathrm{kK}$ & $\nu_{2}, \mathrm{kK}$ & $\nu_{1}, \mathrm{kK}$ & Solvent \\
\hline $\begin{array}{l}\mathrm{KCO}(\mathrm{bi})_{2} \\
\mathrm{Bu}_{4} \mathrm{NCo}(\mathrm{bi})_{2}\end{array}$ & 3.4 & -150 to +100 & 0 & $\begin{array}{l}13.2 \\
13.3 \mathrm{sh} \\
13.2\end{array}$ & $\begin{array}{l}12.7 \\
12.6(100) \\
12.8\end{array}$ & $\begin{array}{l}11.2 \\
11.6(50) \\
11.5\end{array}$ & $\begin{array}{l}\text { Solid } \mathrm{KBr} \\
\mathrm{C}_{2} \mathrm{H}_{5} \mathrm{OH} \\
\text { DMSO }\end{array}$ \\
\hline $\mathrm{KCo}(3-\operatorname{Pr}(\mathrm{bi}))_{2}\left(1-\operatorname{Pr}(\mathrm{bi}) \mathrm{H}_{2}\right)_{2}$ & $\begin{array}{l}3.3 \\
3.4 \text { (DMSO) }\end{array}$ & -150 to +20 & -16 & $\begin{array}{l}13.4 \mathrm{sh} \\
13.4 \\
13.7\end{array}$ & $\begin{array}{l}12.8(107) \\
12.8 \\
13.3\end{array}$ & $\begin{array}{l}11.5(51) \\
11.5 \\
11.4\end{array}$ & $\begin{array}{l}\text { DMSO } \\
\mathrm{C}_{2} \mathrm{H}_{5} \mathrm{OH} \\
\text { Solid KBr }\end{array}$ \\
\hline $\begin{array}{l}\mathrm{KCo}(3-\operatorname{Pr}(\mathrm{bi}))_{2} \cdot 2 \mathrm{DMSO} \\
\mathrm{KCo}(3-\mathrm{Pr}(\mathrm{bi}))_{2} \cdot 2 \mathrm{H}_{2} \mathrm{O}\end{array}$ & $\begin{array}{l}3.5 \\
3.4 \\
3.5 \text { (DMSO) }\end{array}$ & $\begin{array}{l}-150 \text { to }+20 \\
-250 \text { to }+20\end{array}$ & $\begin{array}{c}d \\
-19\end{array}$ & & $13.1(100)$ & $11.4(50)$ & DMSO \\
\hline $\mathrm{KCo}(3-\mathrm{Ph}(\mathrm{bi}))_{2} \cdot 2 \mathrm{DMSO}$ & 3.5 & -150 to +20 & $d$ & & 12.8 & 11.1 & $\mathrm{C}_{2} \mathrm{H}_{5} \mathrm{OH}$ \\
\hline $\begin{array}{l}\mathrm{Bu}_{4} \mathrm{NCo}\left(\mathrm{en}(\mathrm{bi})_{2}\right) \\
\mathrm{KCo}\left(o \text {-phen }(\mathrm{bi})_{2}\right)\end{array}$ & $\begin{array}{l}3.3 \\
3.1\end{array}$ & -150 to +20 & -20 & $\begin{array}{l}13.0(140) \\
13.8(1240)\end{array}$ & $12.2 \mathrm{sh}$ & $\begin{array}{l}11.5(40) \\
11.2(600)\end{array}$ & $\begin{array}{l}\text { DMSO } \\
\text { DMSO }\end{array}$ \\
\hline $\mathrm{Bu}_{4} \mathrm{NCo}\left(o-\operatorname{phen}(\mathrm{bi})_{2}\right) \cdot \mathrm{CHCl}_{3}$ & 3.4 & -150 to +20 & -20 & $13.8(1200)$ & & $11.2(600)$ & DMSO \\
\hline
\end{tabular}

a Corrections for diamagnetism taken from J. M. Kolthoff and P. J. Elving, "Treatise on Analytical Chemistry," Part I, Vol. 4, Interscience, New York, N. Y., 1963, pp 1778-1781. ${ }^{b}$ Only bands with small extinction coefficients given. Extinction coefficients in parenthëses. ${ }^{c}$ At room temperature. Measured on solid samples, unless solvent is indicated. $d$ Not exactly determined due to inaccuracy in measurement.

The precipitate of the crude red complex was then filtered off. It was dissolved in DMSO, the solution was filtered, and the complex was precipitated by adding chloroform and ether.

Anal. Calcd for $\mathrm{Bu}_{4} \mathrm{NCo}\left(\mathrm{en}(\mathrm{bi})_{2}\right)$ : C, $49.90 ; \mathrm{H}, 8.38 ; \mathrm{N}, 18.51$. Found: $\mathrm{C}, 48.1 ; \mathrm{H}, 8.3 ; \mathrm{N}, 18.8$.

$\left.\mathrm{Bu}_{4} \mathrm{NCO}(O \text {-phen(bi) })_{2}\right) \cdot \mathrm{CHCl}_{3}$. In $15 \mathrm{ml}$ of DMSO, $\mathrm{CoCl}_{2} \cdot 6 \mathrm{H}_{2} \mathrm{O}$ $(0.5 \mathrm{~g})$ and $o$-phenylenebis(biuret) $(0.56 \mathrm{~g})$ were dissolved and $5 \mathrm{ml}$ of a $40 \% \mathrm{Bu}_{4} \mathrm{NOH}$ solution in water was added. Then, with stirring, water $(15 \mathrm{ml})$ was added to the mixture and the resulting slurry was oxidized with air during $0.5 \mathrm{hr}$. The purple precipitate of the crude complex was filtered off. It was dissolved in DMSO, the solution was filtered, and small purple needles of the pure complex were obtained when chloroform was added to this solution.

Anal. Calcd for $\mathrm{Bu}_{4} \mathrm{NCo}\left(o\right.$-phen(bi) $\left.{ }_{2}\right) \cdot \mathrm{CHCl}_{3}$ : C, 46.6; $\mathrm{H}, 6.2$; $\mathrm{N}, 14.09$. Found: $\mathrm{C}, 46.3 ; \mathrm{H}, 6.3 ; \mathrm{N}, 14.13$.

The presence of chloroform was confirmed by the mass spectrum of the compound at $120^{\circ}$.

All these complexes do not have good melting points but decompose in general above $170^{\circ}$.

Physical Measurements. Magnetic susceptibilities were measured with Gouy type equipment with $\mathrm{HgCo} \mathrm{NCS})_{4}^{-}$as a reference over a temperature range of -150 to $+20^{\circ}$. A vibrating-sample magnetometer (Princeton Applied Research Type 155) equipped with a standard PAR temperature control unit was used in the temperature range of $4.2-120^{\circ} \mathrm{K}$. The temperatures in this range were calculated from the magnetic susceptibility of a sample of $\mathrm{KCr}\left(\mathrm{SO}_{4}\right)_{2} \cdot 12 \mathrm{H}_{2} \mathrm{O}^{7}$ The field strength was $16563 \mathrm{G}$. Polarographic data were obtained with a Metrohm Polarecord E261. Dry vacuum-distilled DMSO was used as solvent with $0.1 \mathrm{M} \mathrm{Bu} \mathrm{NClO}_{4}$ as supporting electrolyte. A dropping mercury electrode was used $v s$. a saturated calomel electrode. Ultraviolet and visible spectra were measured with a Unicam SP 700C; transmission spectra were measured in solid $\mathrm{KBr}$ with a Cary Model 14.

\section{Results and Discussion}

Paramagnetic compounds in which $\mathrm{Co}$ (III) is coordinated with four atoms in an essentially planar geometry are very rare. Except for some cobalt(III) dithiolate complexes no good examples are known. Apparently the electron-donating capacity of the biuretato and the dithiolato ligands is so strong that the relatively large electron density on the central cobalt atom makes coordination of strong electrondonating ligands (e.g., amines) unfavorable, while there is in the case of the biuretato complexes no indication of coordination with weak electron donors (e.g., $\mathrm{H}_{2} \mathrm{O}$, DMSO, alcohol). Sometimes, however, the solid compounds contain DMSO, $\mathrm{H}_{2} \mathrm{O}$, or 1 -alkylbiuret. It has been shown by crystallographic structure determination ${ }^{4}$ that the 1 -alkylbiuret

(7) C. M. Herzfeld, "Temperature. Its Measurement and Control in Science and Industry," Vol. 3, Part 1, Reinhold, London, 1962 , p 83 .



Figure 1. Electronic spectrum of $\mathrm{KCo}(3-\operatorname{Pr}(\mathrm{bi}))_{2}\left(1-\operatorname{Pr}(\mathrm{bi}) \mathrm{H}_{2}\right)_{2}$ in DMSO.

molecules are not coordinated with the cobalt atom and that the cobalt atom is in planar coordination with four nitrogen atoms of deprotonated 3-alkylbiurets. Through formation of $\mathrm{H}$ bridges the 1-alkylbiuret molecules are incorporated in the crystal lattice around the potassium ions, yielding compounds which can at best be formulated as $\left[\mathrm{K}\left(1 \text {-alkyl(bi) } \mathrm{H}_{2}\right)_{2}\right]\left[\mathrm{Co}(3 \text {-alkyl(bi) })_{2}\right]$. Compounds of this composition are insoluble in water, so the coincidental presence of 1 -alkylbiuret in the reaction mixture from which these compounds are prepared (see Experimental Part) enabled us to prepare these compounds from aqueous solutions. The $\mathrm{CoN}_{4}$ complexes that are soluble in water (e.g., $\left.\mathrm{KCo}(3-\mathrm{Pr}(\mathrm{bi}))_{2} \cdot 2 \mathrm{DMSO}\right)$ are decomposed in neutral or acid solution, due to protonation of the ligand, so they have to be prepared in nonaqueous solvents such as DMSO. We believe that the cobalt atom in the solid compounds containing DMSO or $\mathrm{H}_{2} \mathrm{O}$ is also four-coordinated, as the spectral and magnetic properties of these compounds are similar to those of the compound containing 1-alkylbiuret (see Table I and Figure 1).

These complexes could be studied in solutions of rather weak electron-donating solvents such as alcohol, DMSO, and acetone, as they do not take up weak electron donors as further ligands. The magnetic moments of $\mathrm{KCo}(3-\operatorname{Pr}(\mathrm{bi}))_{2}$. $2 \mathrm{H}_{2} \mathrm{O}$ and $\mathrm{KCo}(3-\mathrm{Pr}(\mathrm{bi}))_{2}\left(1-\operatorname{Pr}(\mathrm{bi}) \mathrm{H}_{2}\right)_{2}$ in DMSO solution indicate that the triplet ground state is not affected and the positions of the uv-vis absorption bands of $\operatorname{KCo}(3-\operatorname{Pr}(b i))_{2}=$ (1-Pr $($ bi $\left.) H_{2}\right)_{2}$ measured in DMSO, alcohol, and the solid compound are quite the same, indicating that the solvent molecules are not interacting with the planar $\mathrm{CoN}_{4}$ species. 
Table II. Uv Spectral Data of Some Mixed-Ligand Complexes

\begin{tabular}{lcccc}
\hline \multicolumn{1}{c}{ Compd } & $\nu_{1}, \mathrm{kK}$ & $\nu_{2}, \mathrm{kK}$ & $10 D q, \mathrm{kK}$ & $B, \mathrm{~K}$ \\
\hline $\mathrm{Co}(3-\operatorname{Pr}(\mathrm{bi}))_{2}\left(\mathrm{NH}_{3}\right)_{2}{ }^{-}$ & $20.4(70)$ & $27.4 \mathrm{sh}$ & 21.4 & 500 \\
$\mathrm{Co}(3-\operatorname{Pr}(\mathrm{bi}))_{2}\left(\mathrm{C}_{3} \mathrm{H}_{7} \mathrm{NH}_{2}\right)_{2}{ }^{-}$ & $18.5(45)$ & $27.8 \mathrm{sh}$ & 19.0 & 730 \\
$\mathrm{Co}(3-\mathrm{Pr}(\mathrm{bi}))_{2}\left(\mathrm{pyrrolidine}_{2}{ }_{2}^{-}\right.$ & $17.4(42)$ & & & \\
$\mathrm{Co}(3-\operatorname{Pr}(\mathrm{bi}))_{2}(\mathrm{py})_{2}{ }^{-}$ & $18.2(47)$ & & &
\end{tabular}

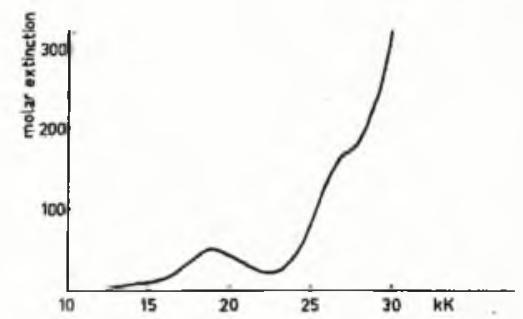

Figure 2. Electronic spectrum of $\mathrm{KCo}(3-\mathrm{Pr}(\mathrm{bi}))_{2}\left(\mathrm{C}_{3} \mathrm{H}_{7} \mathrm{NH}_{2}\right)_{2}$ in ethanol.

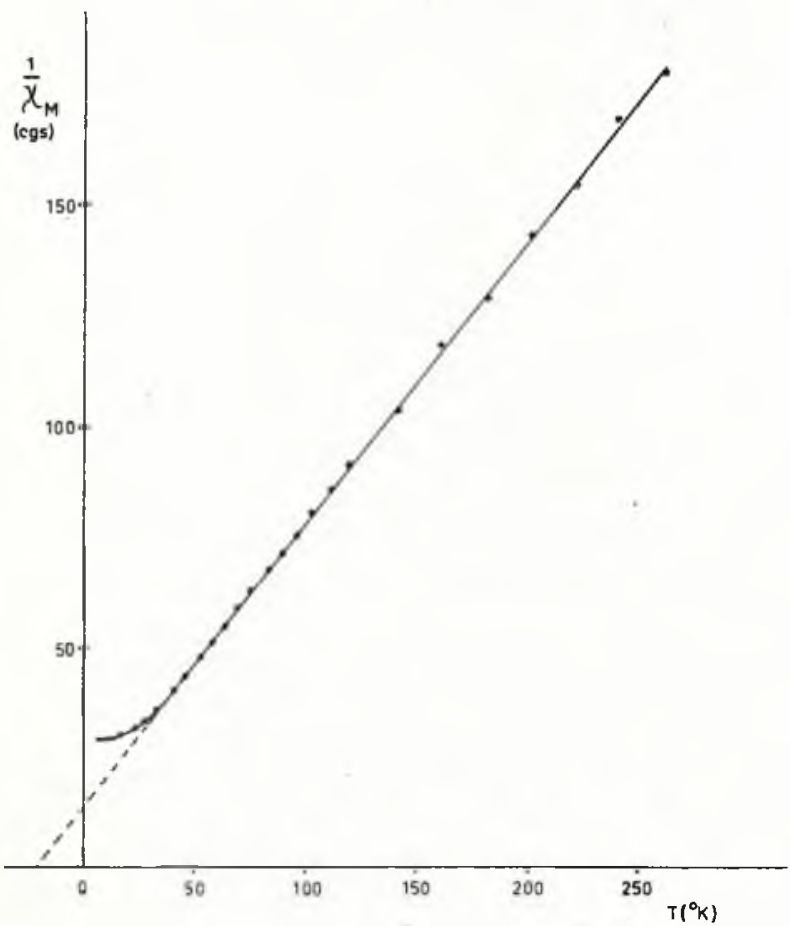

Figure 3. Plot of $1 / \chi_{M}$ vs. $T$ of $\mathrm{KCo}(3-\mathrm{Pr}(\mathrm{bi}))_{2}-2 \mathrm{H}_{2} \mathrm{O}$ (corrected for diamagnetism).

When excess of an amine is added to an alcoholic solution of these paramagnetic cobalt complexes, diamagnetic sixcoordinated adducts are formed. ${ }^{3}$ They can be isolated by adding ether to such a solution. These adducts are thermally unstable in the solid phase. They lose two amine molecules as was indicated by a gravimetric determination at $80^{\circ}$ and the parent four-coordinated paramagnetic complex is left. The uv-vis spectra of these $\mathrm{CoN}_{4} \mathrm{~L}_{2}$ compounds can readily be interpreted as for $\mathrm{Co}$ (III) in an octahedral environment (see Table II and Figure 2).

The magnetic moments of all the planar $\mathrm{CoN}_{4}$ compounds indicate a triplet ground state. Their magnetic susceptibilities obey the Curie-Weiss law over a temperature range of -150 to $+20^{\circ}$. The susceptibility of $\mathrm{KCo}(3-\operatorname{Pr}(\mathrm{bi}))_{2}$. $2 \mathrm{H}_{2} \mathrm{O}$ has been measured from 6.45 to $300^{\circ} \mathrm{K}$. Below $40^{\circ} \mathrm{K}$ the magnetic susceptibility clearly deviates from the CurieWeiss behavior (see Figure 3).

With the usual spin Hamiltonian for describing spin-triplet states the energy levels of a spin triplet in a magnetic field are obtained as given by Ballhausen. ${ }^{8}$
Writing square root terms of the type

$1 / 2 \sqrt{(D+E)^{2}+4 g_{x}{ }^{2} \beta^{2} H_{x}{ }^{2}}$ as $\simeq[(D+E) / 2]+\left[g_{x}{ }^{2} \beta^{2} H_{x}{ }^{2} /\right.$ $(D+E)]$, all symbols having their usual significance, the energies of these levels can be written as a constant plus a function of $H^{2}$, so in the general form ${ }^{9}$

$U_{n}=U_{n}(0)+U_{n}(1) H+U_{n}(2) H^{2}$

$U_{n}(1)$ is always zero in these cases. Now inserting these values into van Vleck's formula

$\chi_{\mathbf{M}}=\frac{N \sum_{n}\left[\frac{\left(U_{n}(1)\right)^{2}}{k T}-2 U_{n}(2)\right] \exp \left(\frac{-U_{n}(0)}{k T}\right)}{\sum_{n} \exp \left(-U_{n}(0) / k T\right)}$

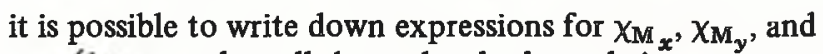
$\chi_{\mathbf{M}_{z}}$ (i.e., $\chi_{\mathbf{M}}$ when all the molecules have their $x, y$, or $z$ axis, respectively, parallel with the magnetic field). The bulk susceptibility of the powdered sample will then be

$\chi_{M}=\frac{\chi_{M_{x}}+\chi_{M_{y}}+\chi_{M_{z}}}{3}$

This results in

$$
\begin{aligned}
\chi_{\mathrm{M}}= & \frac{N \beta^{2}}{3\left(1+\exp \left(-\frac{D+E}{k T}\right)+\exp \left(-\frac{D-E}{k T}\right)\right)}\left[\frac{g_{z}{ }^{2}}{E} \times\right. \\
& \left(\exp \left(-\frac{D-E}{k T}\right)-\exp \left(-\frac{D+E}{k T}\right)\right)+\frac{2 g_{x}{ }^{2}}{D+E}(1- \\
& \left.\left.\exp \left(-\frac{D+E}{k T}\right)\right)+\frac{2 g_{y}^{2}}{D-E}\left(1-\exp \left(-\frac{D-E}{k T}\right)\right)\right]
\end{aligned}
$$

At low temperatures this expression for $\chi_{M}$ approximates $\chi_{M}=\frac{2 N \beta^{2}}{3}\left(\frac{g_{x}{ }^{2}}{D+E}+\frac{g_{y}{ }^{2}}{D-E}\right)$

This means that at low temperatures $\chi$ is independent of the temperature which is in agreement with our measurements. In order to obtain a rough estimate for the value of $D$, we set $E$ equal to zero and take for $g_{x}$ and $g_{y}$ the value of 2 . The measured constant low-temperature $1 / \chi_{M}$ equals 29.3 so $D=81.4 \times 10^{-16} \mathrm{erg}=40.9 \mathrm{~cm}^{-1}$.

This zero-field splitting value is of the same order of magnitude as. found by Dale ${ }^{10}$ for iron(II) phthalocyanine where $D=69.9 \mathrm{~cm}^{-1}$. At higher temperatures the expression for $\chi_{\mathrm{M}}$ approximates

$\chi_{M}=\frac{2 N \beta^{2}}{3(3 k T-2 D)}\left(g_{x}{ }^{2}+g_{y}{ }^{2}+g_{z}{ }^{2}\right)$

This formula has the Curie-Weiss form $\chi=C /(T-\Theta)$ which is also in agreement with our measurements.

Extended Huckel molecular orbital calculations are consistent with a triplet ground state for these planar $\mathrm{CoN}_{4}$ complexes. The calculations were carried out using the VSIP's published by Basch, et al., ${ }^{11}$ as diagonal elements $H_{i i}=\left\langle\mathrm{aO}_{i}|H| \mathrm{ao}_{i}\right\rangle$ in the Hamiltonian matrix and using the Wolfsberg-Helmholz ${ }^{12}$ approximation for the estimation of

(8) C. J. Ballhausen, "Introduction to Ligand Field Theory," McGraw-Hill, New York, N. Y., 1962, p 138.

(9) S. F. A. Kettle, "Coordination Compounds," Nelson Ltd. London, 1969, p 140.

(10) B. W. Dale, R. J. P. Williams, C. E. Johnson, and T. L. Thorp, J. Chem. Phys., 49, 3441 (1968).

(11) H. Basch, A. Viste, and H. B. Gray, Theor. Chim. Acta, 3, $458(1965)$. (1952). 
Table IIL. Coefficients of Co 3d Atomic Orbitals in the Four Highest Filled and the First Empty Molecular Orbitals, together with the Energies of These Orbitals for Different Values of the Wolfsberg-Helmholz Parameter $K$

\begin{tabular}{|c|c|c|c|c|c|c|}
\hline & \multicolumn{2}{|c|}{$K=2.50$} & \multicolumn{2}{|c|}{$K=2.00$} & \multicolumn{2}{|c|}{$K=1.75$} \\
\hline & Coeff & Energy, eV & Coeff & Energy, eV & Coeff & Energy, eV \\
\hline $\begin{array}{l}d_{x y} \\
d_{x^{2}-y^{2}} \\
d_{x z} \\
d_{y z} \\
d_{z^{2}}\end{array}$ & $\begin{array}{r}0.93382 \\
-0.95914 \\
0.98489 \\
0.97602 \\
0.94288\end{array}$ & $\begin{array}{l}-4.01319 \\
-9.13753 \\
-9.13893 \\
-9.30084 \\
-9.36949\end{array}$ & $\begin{array}{r}0.94451 \\
-0.93858 \\
0.98419 \\
-0.97604 \\
-0.92295\end{array}$ & $\begin{array}{r}-8.05548 \\
-11.68261 \\
-11.68973 \\
-11.80467 \\
-11.83599\end{array}$ & $\begin{array}{l}-0.94919 \\
-0.90342 \\
-0.98145 \\
-0.97741 \\
-0.88887\end{array}$ & $\begin{array}{l}-10.86347 \\
-13.76943 \\
-13.76865 \\
-13.84998 \\
-13.87696\end{array}$ \\
\hline
\end{tabular}

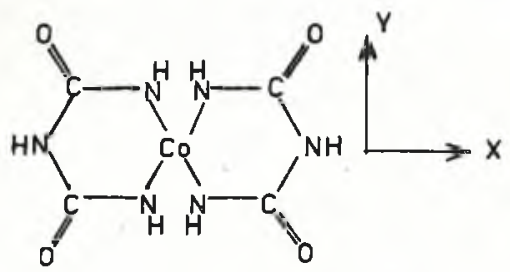

Figure 4. Axis system chosen for the extended Huckel calculations.

the off-diagonal elements $\left\langle\mathrm{ao}_{i}|H| \mathrm{aoo}_{j}\right\rangle=\left[\left(H_{i i}+H_{j j}\right) / 2\right] S_{i j} K$. Atomic orbitals were described by single- $\zeta$ Slater-type orbitals for $s$ and $p$ orbitals with $\zeta$ values taken from Clementi and Raimondi ${ }^{13}$ and from Richardson, et al. ${ }^{14}$ and double$\zeta$ functions were used for the description of the Co $3 \mathrm{~d}$ orbitals taken from Richardson, et al. . $^{15}$ The MO diagram of the unsubstituted $\mathrm{Co}(\mathrm{bi})_{2}{ }^{-}$ion was calculated using interatomic distances as in the alkyl-substituted complex. ${ }^{4}$ Assuming $D_{2 h}$ symmetry average values were used for the bond lengths. The cartesian axes system used is given in Figure 4. Iterative calculations were performed using a charge criterion of 0.002 . Three different values for the WolfsbergHelmholz parameter $K$ were used $(2.50,2.00,1.75)$. The d orbitals show little overlap with ligand orbitals. There are five molecular orbitals which have very large coefficients for the Co $3 \mathrm{~d}$ atomic orbitals and they can be considered as almost pure $d$ orbitals (see Table III). The energy difference between these molecular orbitals appeared to be strongly dependent on the value of $K$. Quantitative correlation between observed spectra and calculated d-orbital splittings cannot be expected to exist due to the inherent inaccuracy in the Huckel approximation. The most important result of these calculations is that the $\mathrm{d}_{x z}$ and $\mathrm{d}_{x^{2}-y^{2}}$ orbitals have almost the same energy for all values of $K$ (see Table III). The configuration $\left(d_{x z}\right)^{1}\left(d_{x^{2}-y^{2}}\right)^{1}$ is in excellent agreement with the observed magnetic triplet ground state which is retained even at temperatures as low as $6^{\circ} \mathrm{K}$. The calculated d-orbital sequence is the same as found by Shupack, et al. ${ }^{16}$ for $\mathrm{Ni}(\mathrm{mnt})_{2}{ }^{2-}$ and used by Baker-Hawkes, et al., ${ }^{17}$ to explain the paramagnetism of $\mathrm{Co}(\mathrm{tdt})_{2}{ }^{-}$.

One of the molecular orbitals which is occupied by an unpaired electron has $x z$ symmetry. It is largely built up from the $\operatorname{Co~}_{x z}$ atomic orbital but there is also a contribution from all the $\mathrm{p}_{z}$ orbitals of the ligand atoms. The $\mathrm{p}_{z}$ orbital of the nitrogen atom on the 3 position has a coefficient of about 0.1 (see Table IV). In view of this fact it is not surprising that the value of the polarographic halfwave potential is in part determined by the nature of the substituent on the remote 3 position as its influence can be

(13) E. Clementi and D. L. Raimondi, J. Chem. Phys., 38, $2686(1963)$.

(14) J. W. Richardson, R. R. Powell, and W. C. Nieuwpoort, J. Chem. Phys., 38, 796 (1963).

(15) J. W. Richardson, W. C. Nieuwpoort, R. R. Powell, and W. F. Edgell, J. Chem. Phys., 36, 1057 (1962).

(16) S. S. Shupack, E. Billig, R. J. H. Clark, R. Williams, and H. B. Gray, J. Amer. Chem. Soc., 86, 4594 (1964).

(17) M. J. Baker-Hawkes, E. Billig, and H. B. Gray, J. Amer. Chem. Soc., 88, 4870 (1966).
Table IV. Coefficients of $p_{z}$ Atomic Orbitals of Ligand Atoms in the MO that Largely Consists of Co $3 \mathrm{~d}_{x z}$<smiles>CC1NC(O)NC(O)N1</smiles>

\begin{tabular}{lccc}
\hline & $K=2.50$ & $K=2.00$ & $K=1.75$ \\
\hline$C o d_{x z}$ & 0.98489 & 0.98419 & 0.98145 \\
$\mathrm{~N}_{1} \mathrm{p}_{z}$ & 0.08416 & 0.08792 & 0.10043 \\
$C \mathrm{p}_{z}$ & 0.05172 & 0.04938 & 0.03690 \\
$O \mathrm{p}_{z}$ & 0.04716 & 0.04549 & 0.04324 \\
$\mathrm{~N}_{2} \mathrm{p}_{z}$ & 0.08425 & 0.08744 & 0.09744
\end{tabular}

Table V. Polarographic Data ${ }^{a}$

\begin{tabular}{lcc}
\hline Compd & $E_{1 / 2}, \mathrm{~V}$ & $E_{3 / 4}-E_{1 / 4}, b \mathrm{mV}$ \\
\hline $\mathrm{KCo}(3-\operatorname{Pr}(\mathrm{bi}))_{2}-2 \mathrm{H}_{2} \mathrm{O}$ & -0.71 & 60 \\
$\mathrm{KCo}(3-\mathrm{Ph}(\mathrm{bi}))_{2}-2 \mathrm{DMSO}$ & -0.64 & 58 \\
$\left.\mathrm{Bu} \mathrm{NCo}_{4} \mathrm{Ni}\right)_{2}$ & -0.65 & 64 \\
$\mathrm{Bu}_{4} \mathrm{NCo}\left(\mathrm{en}(\mathrm{bi})_{2}\right)$ & -0.63 & 60 \\
$\mathrm{KCo}\left(o-\mathrm{phen}(\mathrm{bi})_{2}\right)$ & -0.47 & 60
\end{tabular}

a All potentials were measured with $0.1 \mathrm{~N} \mathrm{Bu}_{4} \mathrm{NClO}_{4}$ as : supporting electrolyte. All waves were of the reduction type. $b$ Theoretical value: $(R T / n F) \ln 9$. At $20^{\circ}$ this value is $55.5 \mathrm{mV}$ for a reversible one-electron transfer.

transferred through the delocalized $\pi$-electron system up to the cobalt atom (see Table $V$ ). The influence of a $\pi$ electron-withdrawing substituent on the 1 position has a much more pronounced effect as can be seen in Table $\mathrm{V}$ comparing the half-wave potentials of the ethylenebis(biuret) complex with that of the $o$-phenylenebis(biuret) complex.

As the molecular orbitals in which the unpaired electrons are present have $x z$ and $x^{2}-y^{2}$ symmetry, the electronic ground state in $D_{2 h}$ symmetry is ${ }^{3} \mathrm{~B}_{2 \mathrm{~g}}$. All compounds have $D_{2 h}$ symmetry except the $o$-phenylenebis(biuret) and the ethylenebis(biuret) complex. In the latter no extensive delocalization over the ethylene bridge is possible. In the $o$-phenylenebis(biuret) complex the $x z$ molecular orbital, consisting of the Co $3 \mathrm{~d}_{x z}$ atomic orbital and all ligand $\mathrm{p}_{z}$ orbitals, has no center of symmetry in contrast with the situation in any other of the compounds reported here. So some transitions"involving this orbital will no longer be Laporte forbidden. This accounts for the larger extinction coefficients found for some of the d-d transitions in the $o$-phenylenebis(biuret) complex.

\section{Conclusions}

The paramagnetic ( $S=1$ ) cobalt(III)-bis(biuretato) complexes show a normal Curie-Weiss magnetic behavior from room temperature down to $-150^{\circ}$. Below $50^{\circ} \mathrm{K}$ deviation from the Curie-Weiss behavior occurs due to zero-field splitting but the triplet ground state is not affected. The unpaired electrons are largely localized in the Co $3 \mathrm{~d}_{x z}$ and $3 d_{x^{2}-y^{2}}$ atomic orbitals. The polarographic half-wave po- 
tentials are dependent on the nature of substituents on the biuret ligand probably due to electron donating or withdrawing through the delocalized $\pi$-electron system which overlaps with the Co $3 \mathrm{~d}_{x z}$ orbital.

Registry No. $\mathrm{KCo}(\mathrm{bi})_{2}, 38637-46-6 ; \mathrm{KCo}(3-\mathrm{Ph}(\mathrm{bi}))_{2}$. 2DMSO, 38637-47-7; $\mathrm{Bu}_{4} \mathrm{NCo}(3-\mathrm{Ph}(\mathrm{bi}))_{2}$, 38637-48-8; $\mathrm{Bu}_{4} \mathrm{NCo}(\mathrm{bi})_{2} \cdot \mathrm{H}_{2} \mathrm{O}, 38637-49-9 ; \mathrm{KCo}(3-\operatorname{Pr}(\mathrm{bi}))_{2}\left(1-\operatorname{Pr}(\mathrm{bi}) \mathrm{H}_{2}\right)_{2}$, 36472-84-1; $\mathrm{KCo}(3-\mathrm{Pr}(\mathrm{bi}))_{2} \cdot 2 \mathrm{H}_{2} \mathrm{O}, 38637-51-3 ; \mathrm{KCo}(3-\mathrm{Pr}-$ (bi)) 2 -2DMSO, 38637-52-4; $\mathrm{KCo}\left(\mathrm{en}(\mathrm{bi})_{2}\right)$, 38637-53-5; KCo(o-phen(bi) $)_{2}$ ), 38637-54-6; $\mathrm{Bu}_{4} \mathrm{NCo}\left(\mathrm{en}(\mathrm{bi})_{2}\right.$ ), 38637-55-7; $\mathrm{Bu}_{4} \mathrm{NCo}\left(o-p h e n(\mathrm{bi})_{2}\right) \cdot \mathrm{CHCl}_{3}, 38637-56-8 ; \mathrm{KCo}(3-\mathrm{Pr}(\mathrm{bi}))_{2}-$ $\left(\mathrm{NH}_{3}\right)_{2}, 31282-33-4 ; \mathrm{KCo}(3-\mathrm{Pr}(\mathrm{bi}))_{2}\left(\mathrm{C}_{3} \mathrm{H}_{7} \mathrm{NH}_{2}\right)_{2}, 31282-34-$
$5 ; \mathrm{KCo}(3-\mathrm{Pr}(\text { bi }))_{2}$ (pyrrolidine) ${ }_{2}, 31249-56-6 ; \mathrm{KCo}(3-\operatorname{Pr}(\mathrm{bi}))_{2}$ (pyridine) ${ }_{2}, 31240-71-8$.

Acknowledgment. The investigations were supported by The Netherlands Foundation for Chemical Research (SON) with financial aid from The Netherlands Organization for the Advancement of Pure Research. We wish to thank Mr. J. Diersmann for performing the analyses, Dr. C.P. Keijzers for providing the computer program for the Huckel calculations, and Professor L. L. van Reijen for giving us the opportunity to perform magnetic measurements below $150^{\circ} \mathrm{K}$. We thank Dr. P. van der Put for help with the interpretation of magnetic data. 


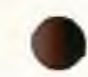

- 